\title{
Human brown adipose tissue $\left[{ }^{15} \mathrm{O}\right] \mathrm{O}_{2}$ PET imaging in the presence and absence of cold stimulus
}

\author{
Mueez u Din ${ }^{1,2} \cdot$ Juho Raiko $^{1,2} \cdot$ Teemu Saari $^{1,2}$ - Nobu Kudomi ${ }^{3}$. Tuula Tolvanen ${ }^{1,2}$. \\ Vesa Oikonen $^{1,2}$ - Jarmo Teuho ${ }^{1,2}$ Hannu T Sipilä ${ }^{1,2} \cdot$ Nina Savisto $^{1,2}$. \\ Riitta Parkkola $^{4}$ - Pirjo Nuutila ${ }^{1,2}$ - Kirsi A. Virtanen ${ }^{1,2}$
}

Received: 30 November 2015 / Accepted: 8 March 2016 /Published online: 19 March 2016

(C) The Author(s) 2016. This article is published with open access at Springerlink.com

\begin{abstract}
Purpose Brown adipose tissue (BAT) is considered a potential target for combatting obesity, as it produces heat instead of ATP in cellular respiration due to uncoupling protein-1 (UCP1) in mitochondria. However, BAT-specific thermogenic capacity, in comparison to whole-body thermogenesis during cold stimulus, is still controversial. In our present study, we aimed to determine human BAT oxygen consumption with $\left[{ }^{15} \mathrm{O}\right] \mathrm{O}_{2}$ positron emission tomography (PET) imaging. Further, we explored whether BAT-specific energy expenditure (EE) is associated with BAT blood flow, non-esterified fatty acid (NEFA) uptake, and whole-body EE.

Methods Seven healthy study subjects were studied at two different scanning sessions, 1) at room temperature (RT) and 2) with acute cold exposure. Radiotracers $\left[{ }^{15} \mathrm{O}\right] \mathrm{O}_{2},\left[{ }^{15} \mathrm{O}\right] \mathrm{H}_{2} \mathrm{O}$, and $\left[{ }^{18} \mathrm{~F}\right] \mathrm{FTHA}$ were given for the measurements of BAT oxygen consumption, blood flow, and NEFA uptake, respectively, with PET-CT. Indirect calorimetry was performed to assess differences in whole-body EE between RT and cold.
\end{abstract}

Electronic supplementary material The online version of this article (doi:10.1007/s00259-016-3364-y) contains supplementary material, which is available to authorized users.

Kirsi A. Virtanen

kirsi.virtanen@utu.fi

1 Turku PET Centre, Turku University Hospital, Kiinamyllynkatu 4-8, 20520 Turku, Finland

2 Turku PET Centre, University of Turku, Kiinamyllynkatu 4-8, 20520 Turku, Finland

3 Department of Medical Physics, Faculty of Medicine, Kagawa University, Kagawa, Japan

4 Department of Radiology, Turku University Hospital and University of Turku, Turku, Finland
Results BAT-specific EE and oxygen consumption was higher during cold stimulus (approx. $50 \%$ ); similarly, whole-body EE was higher during cold stimulus (range 2$47 \%$ ). However, there was no association in BAT-specific EE and whole-body EE. BAT-specific EE was found to be a minor contributor in cold induced whole-body thermogenesis (almost $1 \%$ of total whole-body elevation in EE). Certain deep muscles in the cervico-thoracic region made a major contribution to this cold-induced thermogenesis (CIT) without any visual signs or individual perception of shivering. Moreover, BAT-specific EE associated with BAT blood flow and NEFA uptake both at RT and during cold stimulus.

Conclusion Our study suggests that BAT is a minor and deep muscles are a major contributor to CIT. In BAT, both in RT and during cold, cellular respiration is linked with circulatory NEFA uptake.

Keywords Brown adipose tissue $\cdot$ cold-induced thermogenesis $\cdot$ oxygen consumption $\cdot\left[{ }^{15} \mathrm{O}\right] \mathrm{O}_{2}$ PET imaging

\section{Introduction}

Brown adipose tissue (BAT) provides non-shivering thermogenesis (NST) because of the presence of the mitochondrial uncoupling protein-1(UCP-1) [1] and BAT activity remains present in humans in adulthood [2-4]. Cold exposure stimulates the sympathetic nervous system (SNS), which triggers BAT into heat production [5].

Previous studies showing metabolically active BAT under cold stress are based on high symmetrical bilateral $\left[{ }^{18} \mathrm{~F}\right] \mathrm{FDG}$ uptake in supraclavicular adipose tissue regions [6-9], while active BAT is considered to rely primarily on fatty acids as the major fuel for thermogenesis [10]. The study by Muzik et al. [11] has shown that during cold stress higher $\left[{ }^{18} \mathrm{~F}\right] \mathrm{FDG}$ 
standardised uptake values (SUVs) correlate with higher oxygen consumption in BAT. However, a proportional glucose contribution as a BAT substrate could not be suggested in this study due to the static $\left[{ }^{18} \mathrm{~F}\right]$ FDG PET measurements. Moreover, BAT-specific energy expenditure (EE) during cold is unclear [12], while the study by Muzik et al. [11] suggests BAT to be a minor contributor to cold induced thermogenesis. Therefore, it was critical to confirm BAT-specific EE using direct oxygen consumption measurements by using $\left[{ }^{15} \mathrm{O}\right] \mathrm{O}_{2}$ positron-emission tomography (PET) imaging. Moreover, it has also not yet been established how much of the BAT circulatory NEFA uptake is associated with BAT-specific thermogenesis.

In the present study, we hypothesized that increased oxygen consumption by brown adipocytes under cold stimulation can be identified using in vivo $\left[{ }^{15} \mathrm{O}\right] \mathrm{O}_{2}$ PET imaging in human supraclavicular BAT depots, and we further aimed to determine whether BAT-associated EE correlates with whole-body EE and additionally with BAT blood flow and NEFA uptake in room temperature (RT) conditions and during cold stimulus.

\section{Material and methods}

\section{Study subjects}

Healthy study subjects $(n=7)$ of both genders with normal oral glucose tolerance test and cardiovascular status were included after written informed consent and screening. Subjects were screened for hypertension, diabetes, and elevated hepatic enzymes (ALAT, AFOS, GT). Whole-body insulin sensitivity (M-value) was also measured using a hyperinsulinemic euglycemic clamp technique [13]. The basic characteristics are given in Table 1. The local ethical review committee of the Southwestern Finland Hospital District reviewed and approved the study.

Table 1 Characteristics of study subjects

\begin{tabular}{llc}
\hline Age & years & $36 \pm 11$ \\
\hline Gender & $\mathrm{M} / \mathrm{F}$ & $5 / 2$ \\
BMI & $\mathrm{kg} / \mathrm{m}^{2}$ & $25.5 \pm 3.3$ \\
Waist & $\mathrm{cm}$ & $90.4 \pm 10.4$ \\
M-value* & $\mathrm{mg} / \mathrm{kg} / \mathrm{min}$ & $6.9 \pm 3.7$ \\
Percentage fat & $\%$ & $24.8 \pm 9.1$ \\
Body surface area & $\mathrm{m}^{2}$ & $2.0 \pm 0.2$ \\
\hline
\end{tabular}

*M-value describes whole body insulin sensitivity

Abbreviations: BMI: Body mass index

Data is shown as mean $\pm \mathrm{SD}$

\section{Study design}

Subjects underwent two PET scanning sessions; one of the scanning sessions was performed at room temperature and the other during acute cold exposure (Fig. 1). Scanning sessions were organised on separate days in a random order with the minimum interval between the sessions being one week. Studies were performed after overnight fasting. All scans were performed at the same time of day in order to minimise any possible effect caused by individual circadian rhythm. Cold exposure was started $2 \mathrm{~h}$ prior to the scan using cooling blankets (Blanketrol III, Cincinnati Sub-Zero, Cincinnati, OH, USA), and cooling was continued during the PET scanning. Cooling was initiated with the temperature of the water circulating in the cooling blanket set to $6{ }^{\circ} \mathrm{C}$; this temperature was gradually raised once the subjects were visually observed to be shivering or reported shivering themselves. The skin temperature of the subjects was also monitored during scanning using a digital thermometer (Art.183, Termometerfabriken Viking AB, Eskilstuna, Sweden) while the temperature sensing probe attached to the lateral abdominal skin surface. RT was maintained at approximately $22^{\circ} \mathrm{C}$.

\section{Scanning protocol}

Subjects were placed supine in a head first position inside the PET-CT scanner (Discovery 690 PET-CT scanner; General Electric Medical Systems, Milwaukee, WI, USA; PET voxel size $=3.64 \times 3.64 \times 3.27 \mathrm{~mm}$ ), while the level of the clavicles was set to be the centre of the axial field of view (AFOV). Comfortable, relaxed position of the subjects was ensured in order to avoid any tension in the neck muscles, and the arms were placed next to the body. The positioning of the subjects within the scanner was kept identical irrespective the cooling protocol utilised. Scanning started with an attenuation correction transmission CT scan followed by three separate dynamic emission PET scans using three different radiotracers, i.e. $\left[{ }^{15} \mathrm{O}\right] \mathrm{O}_{2},\left[{ }^{15} \mathrm{O}\right] \mathrm{H}_{2} \mathrm{O}$, and $\left[{ }^{18} \mathrm{~F}\right] \mathrm{FTHA}$. In the $\left[{ }^{15} \mathrm{O}\right] \mathrm{O}_{2}$ scans, the subjects were given radioactive oxygen gas (509 $\pm 37 \mathrm{MBq}$ ) using a plastic mask with a single deep inhalation and scanning was started simultaneously; 20 frames of variable lengths were acquired over a period of $7 \min (6 \times 5 \mathrm{~s}$, $6 \times 15 \mathrm{~s}, 6 \times 30 \mathrm{~s}, 2 \times 60 \mathrm{~s})$. After sufficient radioactive decay of $\left[{ }^{15} \mathrm{O}\right] \mathrm{O}_{2}$ (approx. $10 \mathrm{~min}$.), radiowater $\left[{ }^{15} \mathrm{O}\right] \mathrm{H}_{2} \mathrm{O}(493 \pm 35$ $\mathrm{Mbq}$ ) was intravenously injected into the left antecubital vein and scanning started immediately using 20 frames with a dynamic acquisition protocol $(6 \times 5 \mathrm{~s}, 6 \times 15 \mathrm{~s}, 6 \times 30 \mathrm{~s}, 2 \times 60 \mathrm{~s})$. $\left[{ }^{18} \mathrm{~F}\right]$ FTHA scans were performed and quantified as described by Saari et al. [14]. Each subject received an estimated radiation dose of $8.8 \mathrm{mSv}$ from the PET-CT scans during our study. The details of the production of tracers and PET image reconstruction can be found in the supplementary data. 
Fig. 1 Diagrammatic representation of the study design and scanning protocol utilised to measure whole-body energy expenditure, oxidative metabolism, blood flow, and NEFA uptake at room temperature and during cold stimulus. Abbreviations: CT, Xray computed tomography; $\left[{ }^{15} \mathrm{O}\right] \mathrm{O}_{2}$, Radioactive $\mathrm{O}^{15}$ labelled oxygen gas; $\left[{ }^{15} \mathrm{O}\right] \mathrm{H}_{2} \mathrm{O}$, Radioactive $\mathrm{O}^{15}$ labelled water

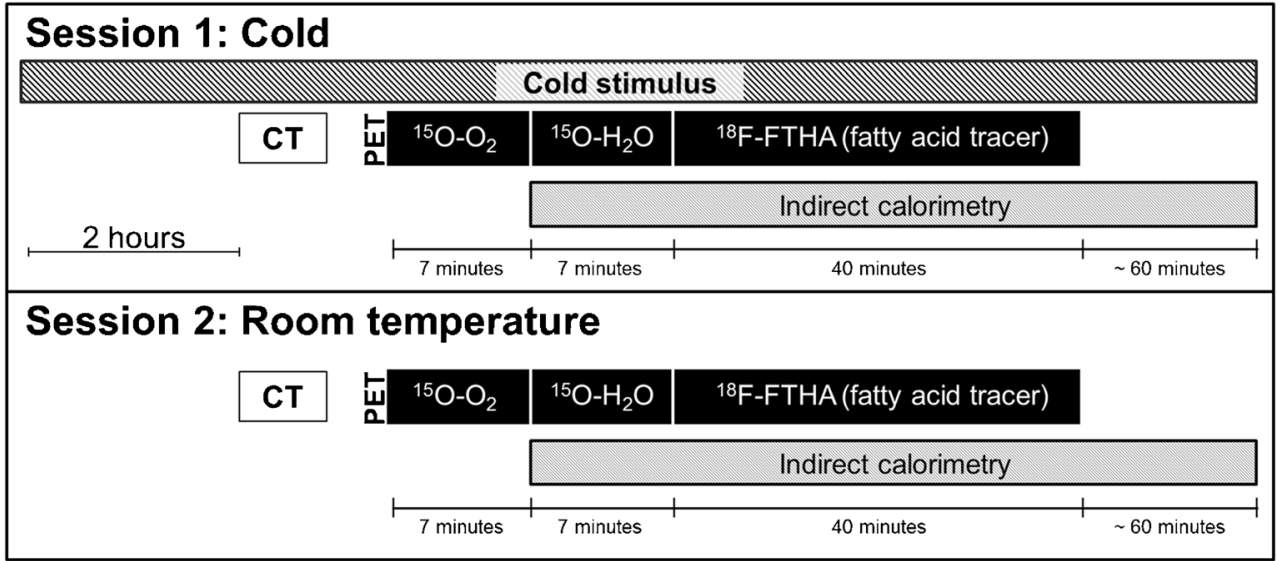

\section{PET image analysis}

Carimas 2.8 software (Turku PET Centre, Turku, Finland) was used to analyse all acquired PET-CT images. The volume of interests (VOIs) in BAT were drawn manually on the supraclavicular fat depots on the fused PET-CT images by taking into account the CT Hounsfield unit (HU) value of the voxels within -50 to $-250 \mathrm{HU}$ range (Fig. 2). White adipose tissue VOIs were drawn on the posterior subcutaneous neck area. For skeletal muscle, VOIs were drawn on deltoid, trapezius, levator scapulae, splenius cervicis, and pectoralis major muscles. For all the radiotracers used, arterial input function was determined by drawing a VOI comprising of 70-100 voxels on the arch of the aorta on the fused PET-CT images.

\section{Measurement of blood flow (BF) and metabolic rate of oxygen $\left(\mathrm{MRO}_{2}\right)$}

Blood flow was calculated from $\left[{ }^{15} \mathrm{O}\right] \mathrm{H}_{2} \mathrm{O}$ PET scans by assuming a one-tissue compartmental model as follows,

$C_{T}(t)=K_{1}^{W} \cdot C_{A}(t) \otimes e^{-K 2 \cdot t}+V_{A} \cdot C_{A}(t)$

where $C_{\mathrm{T}}$ is the tissue time activity curve, $C_{\mathrm{A}}$ is the input function and $V_{\mathrm{A}}$ is the arterial blood volume. The $K_{1}{ }^{\mathrm{w}}, k_{2}$, and $V_{\mathrm{A}}$ values were estimated by an optimization procedure (Gauss-Newton method).

The metabolic rate of oxygen was calculated by incorporating the TACs of $\left[{ }^{15} \mathrm{O}_{0} \mathrm{O}_{2}\right.$ PET scans by assuming a onetissue compartmental model as follows,

$$
\begin{aligned}
C_{T}(t)= & K_{1}{ }^{O} \cdot C_{A}{ }^{O}(t) \otimes e^{-K 2 \cdot t}+K_{1}{ }^{W} \cdot C_{A}{ }^{W}(t) \otimes e^{-K 2 \cdot t} \\
& +V_{0} \cdot C_{A}{ }^{0}(t)
\end{aligned}
$$

where $C_{T}$ is the tissue TAC, $C_{A}{ }^{O}$ and $C_{A}{ }^{w}$ are the input functions for oxygen and water, respectively. For the estimation of oxygen and water content, the aorta TAC was separated for each component according to the mathematical model described by Iida et al. [15]. $V_{0}$ is the arterial blood volume. The first term in the equation expresses the kinetics of oxygen and the second that of water, namely recirculation water. The $K_{1}{ }^{\circ}$, and $V_{0}$ values were estimated by an optimization procedure (Gauss-Newton method), by inputting the obtained $K_{1}{ }^{\text {w }}$ and $k_{2}$ from the water data [16]. Subsequently, the $\mathrm{MRO}_{2}$ in the specific tissue was calculated as a product of $K_{1}{ }^{\mathrm{o}}$ and the arterial oxygen concentration ${ }^{\mathrm{a}} \mathrm{O}_{2}\left(\mathrm{mLO}_{2} / 100 \mathrm{~mL}\right)$. The arterial concentration of oxygen was considered to be $19.8 \mathrm{~mL}$ per $100 \mathrm{~mL}$ of blood volume. $\mathrm{MRO}_{2}$ for muscles was calculated by taking into account the oxygen binding in myoglobin $[17,18]$.

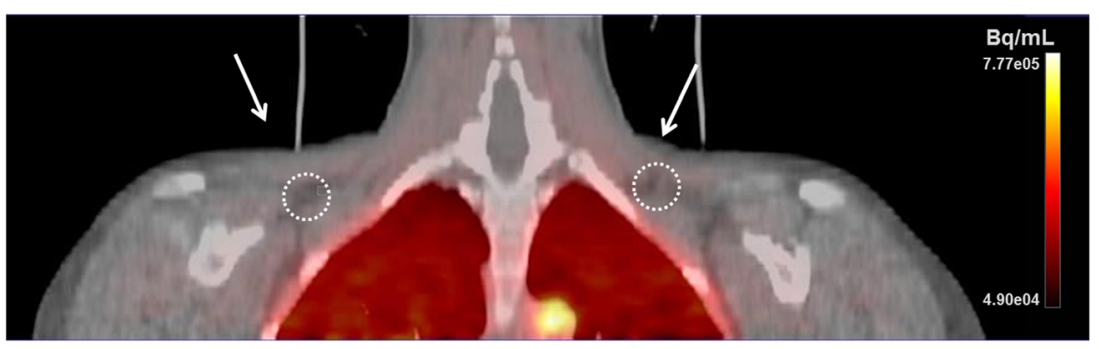

Fig. 2 Fused $\left[{ }^{15} \mathrm{O}\right] \mathrm{O}_{2}$ PET-CT scan showing the location of threedimensional VOIs for BAT in supraclavicular fat depots (white circles). Subjects were asked to inhale $\left[{ }^{15} \mathrm{O}\right]$ labelled $\mathrm{O}_{2}$; therefore, high radioactive concentration (red colour) can be seen in the lungs region.
Arterial input functions were calculated by drawing a VOI on the arch of the aorta (high radioactive concentration can be seen as a yellow bright spot) 


\section{Indirect calorimetry}

In order to measure whole-body $\mathrm{EE}$ and substrate utilisation rates, indirect calorimetry (using Deltatrac II, Datex-Ohmeda) was performed simultaneously with PET scans (100-120 min, Fig. 1). From the data set, measurements were excluded from analyses if they deviated more than 1.5 $\mathrm{SD}$ from the mean $\mathrm{vO}_{2}, \mathrm{vCO}_{2}$, EE or respiratory quotient values, caused by irregular breathing. The first $30 \mathrm{~min}$ of the calorimetry data was also excluded. Whole-body EE, substrate utilisation rates, and respiratory quotient were calculated according to Weir equation [19] and the manufacturer's equations [20] using Matlab (Version: R2011a). Protein oxidation was accounted for in the equations by considering urinary nitrogen to be $13 \mathrm{~g} / 24 \mathrm{~h}$.

\section{Tissues mass calculation}

BAT mass in the cervico-upper thoracic region was estimated on fused PET-CT images by first thresholding all $\mathrm{CT}$ voxels between a range of -50 to $-250 \mathrm{HU}$ at all potential cervico-upper thoracic BAT sites (cervical, supraclavicular, and axillary adipose depots). The acquired voxels underwent further thresholding and all voxels with less than $0.7 \mu \mathrm{mol} / 100 \mathrm{~g} / \mathrm{min}$ NEFA uptake on parametric cold-exposure $\left[{ }^{18} \mathrm{~F}\right] \mathrm{FTHA}$ PET images were excluded. Finally, the volume of all these voxels $\left(\mathrm{cm}^{3}\right)$ was converted into mass by assuming the density of BAT to be $0.92 \mathrm{~g} / \mathrm{cm}^{3}$. Muscle mass in cervico-upper thoracic region was calculated from the $\mathrm{CT}$ images by thresholding all $\mathrm{CT}$ voxels at all muscle sites between 0 to $+250 \mathrm{HU}$. Afterwards, the volume of all these voxels $\left(\mathrm{cm}^{3}\right)$ was converted into mass by assuming the density of muscle to be $1.06 \mathrm{~g} / \mathrm{cm}^{3}$.

\section{Tissue specific DEE calculation}

Finally, tissue specific daily energy expenditure (DEE) was calculated from $\mathrm{MRO}_{2}$ according to the formula below,

$$
\begin{aligned}
\text { DEE tissue }(\mathrm{kcal} / \text { day })= & \mathrm{MRO}_{2}(\mathrm{~mL} / 100 \mathrm{~g} / \mathrm{min}) \\
& \times \text { tissuemass }(100 \mathrm{~g}) \\
& \times 0.0048(\mathrm{kcal} / \mathrm{mL}) \\
& \times 1440(\mathrm{~min} / \text { day })
\end{aligned}
$$

The energy ( $k c a l)$ produced per millilitre of oxygen consumption was assumed to be for respiratory quotient (RQ) of 0.80 (4.801 kcal/ litre $\mathrm{O}_{2}$ consumed) [21].

\section{Statistical analyses}

Statistical analyses were performed using IBM SPSS Statistics (version 22). To test for differences in mean values, a twotailed paired Student t-test and a Wilcoxon rank-sum test were used. Pearson and Spearman's correlation tests were used to analyse correlations. $p$-value of $\leq 0.05$ was considered to be significant.

\section{Results}

\section{Whole-body energy expenditure}

Whole-body EE was significantly higher (range 2-47 \%) after cold stress as compared with RT $(1701 \pm 282$ versus 2052 $\pm 574 \mathrm{kcal} / 24 \mathrm{~h}, p=0.046$, Fig. 3); likewise there was also significant increase in whole-body oxygen consumption $\left(\mathrm{vO}_{2}\right)$ during cold stimulus (RT: $248.3 \pm 40.2$ versus cold: $299.6 \pm 82.3 \mathrm{~mL} / \mathrm{min}, p=0.04-$ Table 2 ). The respiratory quotient (RQ) was not significantly influenced by cold stress (Table 2); however, when whole-body EE was divided into subcomponents, we observed that the whole-body fat oxidation was significantly higher during cold stress, while no difference was seen in whole-body carbohydrate oxidation (Fig. 3).

\section{Tissue specific metabolic rate of oxygen $\left(\mathrm{MRO}_{2}\right)$ and blood flow (BF)}

Our PET imaging results revealed that the metabolic rate of oxygen $\left(\mathrm{MRO}_{2}\right)$ in BAT during cold stimulus was significantly higher when compared to RT $(0.7 \pm 0.3$ versus $1.2 \pm 0.3 \mathrm{~mL} /$ $100 \mathrm{~g} / \mathrm{min}, p=0.01$, RT vs. cold, respectively). The $\mathrm{MRO}_{2}$ in the levator scapulae muscle was also higher during cold stress $(0.1 \pm 0.1$ compared to $0.5 \pm 0.5 \mathrm{~mL} / 100 \mathrm{~g} / \mathrm{min}, p=0.02$, RT vs. cold, respectively). There was a positive trend of increase

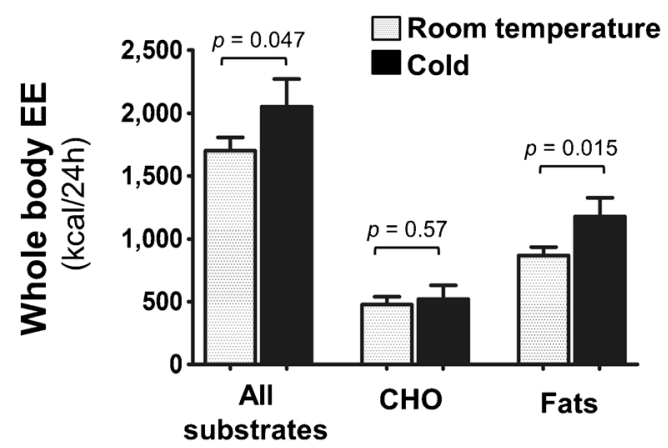

Fig. 3 Whole-body EE (kcal/24 h) measured with indirect respiratory calorimetry was significantly higher during cold stress. Whole-body carbohydrate oxidation was unchanged as a result of cold stress; rather, whole-body fat oxidation was significantly elevated. The result has been shown as mean \pm SEM. Abbreviation: $\mathrm{CHO}$, carbohydrates; EE, energy expenditure 
Table 2 Differences in measured values in room temperature and cold

\begin{tabular}{lllll}
\hline Parameter & & Room Temp. & Cold & p-value \\
\hline Whole-Body EE & $\mathrm{kcal} / 24 \mathrm{~h}$ & $1701 \pm 282$ & $2052 \pm 574$ & 0.047 \\
$\mathrm{RQ}$ & & $0.81 \pm 0.02$ & $0.79 \pm 0.03$ & 0.06 \\
$\mathrm{vO}_{2}$ & $\mathrm{~mL} / \mathrm{min}$ & $248.3 \pm 40.2$ & $299.6 \pm 82.3$ & 0.04 \\
$\mathrm{vCO}_{2}$ & $\mathrm{~mL} / \mathrm{min}$ & $200.2 \pm 34.0$ & $238.2 \pm 67.4$ & 0.06 \\
Average skin temperature & ${ }^{\circ} \mathrm{C}$ & $35.3 \pm 0.8$ & $32.4 \pm 0.8$ & $<0.0001$ \\
BAT NEFA uptake rate & $(\mu \mathrm{mol} / 100 \mathrm{~g} / \mathrm{min})$ & $0.8 \pm 0.8$ & $1.3 \pm 1.3$ & $0.09^{*}$ \\
WAT NEFA uptake rate & $(\mu \mathrm{mol} / 100 \mathrm{~g} / \mathrm{min})$ & $0.3 \pm 0.1$ & $0.3 \pm 0.1$ & 0.60 \\
Deltoid muscle NEFA uptake rate & $(\mu \mathrm{mol} / 100 \mathrm{~g} / \mathrm{min})$ & $0.5 \pm 0.3$ & $0.5 \pm 0.3$ & 0.95 \\
Trapezius muscle NEFA uptake rate & $(\mu \mathrm{mol} / 100 \mathrm{~g} / \mathrm{min})$ & $0.4 \pm 0.2$ & $0.6 \pm 0.3$ & $0.13^{*}$ \\
Levator scapulae muscle NEFA uptake rate & $(\mu \mathrm{mol} / 100 \mathrm{~g} / \mathrm{min})$ & $0.5 \pm 0.2$ & $0.7 \pm 0.3$ & $0.04^{*}$ \\
Splenius cervicis muscle NEFA uptake rate & $(\mu \mathrm{mol} / 100 \mathrm{~g} / \mathrm{min})$ & $0.6 \pm 0.3$ & $0.7 \pm 0.3$ & 0.29 \\
Pectoralis major muscle NEFA uptake rate & $(\mu \mathrm{mol} / 100 \mathrm{~g} / \mathrm{min})$ & $0.4 \pm 0.2$ & $0.8 \pm 0.3$ & 0.06 \\
Plasma Insulin & $\mathrm{mU} / \mathrm{L}$ & $7.1 \pm 8.1$ & $4.8 \pm 2.8$ & 0.46 \\
Free plasma T3 & $\mathrm{pmol} / \mathrm{L}$ & $4.5 \pm 0.4$ & $4.7 \pm 0.3$ & 0.19 \\
Free plasma T4 & $\mathrm{pmol} / \mathrm{L}$ & $14.0 \pm 2.6$ & $14.0 \pm 2.1$ & 1.0 \\
Plasma TSH & $\mathrm{mU} / \mathrm{L}$ & $1.6 \pm 0.6$ & $1.7 \pm 0.6$ & 0.21 \\
Plasma Triglyceride & $\mathrm{mmol} / \mathrm{L}$ & $0.8 \pm 0.3$ & $1.1 \pm 0.4$ & 0.03 \\
Plasma glucose & $\mathrm{mmol} / \mathrm{L}$ & $5.2 \pm 0.3$ & $5.2 \pm 0.2$ & 0.84 \\
\hline
\end{tabular}

Abbreviations: EE, Energy expenditure; RQ, Respiratory Quotient;

T3, Triiodothyronine; T4, Thyroxine; TSH, Thyroid-stimulating hormone

$\mathrm{vO}_{2}$, volume of whole body oxygen consumption; $\mathrm{vCO}_{2}$, volume of whole body carbon dioxide production

Data are shown as mean $\pm \mathrm{SD} *$ Wilcoxon rank-sum test in $\mathrm{MRO}_{2}$ in the pectoralis major (RT: $0.05 \pm 0.04$ versus cold: $0.4 \pm 0.5 \mathrm{~mL} / 100 \mathrm{~g} / \mathrm{min}, p=0.06)$ and splenius cervicis muscles (RT: $0.2 \pm 0.2$, cold: $0.4 \pm 0.3 \mathrm{~mL} / 100 \mathrm{~g} / \mathrm{min}, p=0.15$ ) while there was no difference in $\mathrm{MRO}_{2}$ in the deltoid muscle $(0.1 \pm 0.1$ versus $0.2 \pm 0.2 \mathrm{~mL} / 100 \mathrm{~g} / \mathrm{min}, p=0.60$, RT vs. cold, respectively), trapezius muscle $(0.1 \pm 0.1$ versus 0.2 $\pm 0.3 \mathrm{~mL} / 100 \mathrm{~g} / \mathrm{min}, p=0.29)$ or neck subcutaneous white adipose tissue $(0.5 \pm 0.1$ versus $0.5 \pm 0.1 \mathrm{~mL} / 100 \mathrm{~g} / \mathrm{min}$, $p=0.48$, RT vs. cold, respectively, Fig. 4a).

Similarly, blood flow was significantly higher (almost 2fold) in response to cold in BAT (RT: $5.3 \pm 3.7$ versus cold: $10.0 \pm 2.4 \mathrm{~mL} / 100 \mathrm{~g} / \mathrm{min}, p=0.004$ ), levator scapulae muscle (RT: $5.0 \pm 4.2$ compared to cold: $9.7 \pm 3.5 \mathrm{~mL} / 100 \mathrm{~g} / \mathrm{min}$, $p=0.03$ ), and pectoralis major muscle (RT: $2.3 \pm 1.5 \mathrm{com}$ pared to cold: $5.8 \pm 2.6 \mathrm{~mL} / 100 \mathrm{~g} / \mathrm{min}, p=0.04)$. There was a positive trend of high blood flow in the trapezius muscle (RT: $2.0 \pm 1.3$ compared to cold: $3.2 \pm 1.6 \mathrm{~mL} / 100 \mathrm{~g} / \mathrm{min}$, $p=0.14$ ), while blood flow to the deltoid muscle (RT: 2.5 \pm 1.9 versus cold: $2.2 \pm 1.8 \mathrm{~mL} / 100 \mathrm{~g} / \mathrm{min}, p=0.80)$, and subcutaneous neck white adipose tissue (RT: $2.4 \pm 0.8$ versus cold: $1.7 \pm 0.6 \mathrm{~mL} / 100 \mathrm{~g} / \mathrm{min}, p=0.11$, Fig. $4 \mathrm{~b}$ ) was not significantly different during cold stress.

We found an inverse relation between BMI and BAT $\mathrm{MRO}_{2}$ during cold stress ( $r h o=-0.78 ; p=0.04$ ); moreover, there was also a trend for high radiodense BAT depots (CT radiodensity measured in Hounsfield units) to have higher $\mathrm{MRO}_{2}$ during cold stress $(r=0.68, p=0.08)$.

\section{BAT mass and tissue-associated daily energy expenditure}

BAT masses in the cervico-upper thoracic region were highly varied in our study population with a mean of $133 \pm 59$ grams (range: 55-221 grams). BAT-associated daily energy expenditure (DEE, from $\mathrm{MRO}_{2}$ and BAT mass data), was estimated to be $7 \pm 5 \mathrm{kcal} /$ day at RT compared to $10 \pm 5 \mathrm{kcal} /$ day in cold stress $(p=0.02)$. Change $(\Delta)$ in BAT DEE as a result of cold stress was estimated to be $4 \pm 3 \mathrm{kcal} /$ day; this accounted for merely $1 \%$ of the total change $(\Delta)$ in whole-body EE (352 $\pm 372 \mathrm{kcal} /$ day, a range of 45-898 kcal/day). Moreover, we did not find any obvious direct association between wholebody EE and BAT-associated DEE both at RT (rho $=0.10$, $p=0.81)$ and during cold stress ( $r h o=0.21, p=0.64)$. Paradoxical to earlier findings, we observed significant association between the change $(\Delta)$ in whole-body EE (cold induced thermogenesis $)$ and the BAT mass $(r=0.78 ; p=0.037$, Fig. 5a). We further looked DEE contribution of the cervicoupper thoracic muscles as a means of explaining the high change $(\Delta)$ in whole-body EE, by taking into account muscles $\mathrm{MRO}_{2}$ (average of all analysed muscles, Fig. 4a) and muscle mass. We estimated that the muscles in the cervico-thoracic region (in our FOV, $15 \mathrm{~cm}$ ) contributed $33 \pm 28 \mathrm{kcal} /$ day (range 11-82 kcal/day) during RT and $86 \pm 68 \mathrm{kcal} /$ day (range $11-205 \mathrm{kcal} /$ day, $p=0.058)$ during cold stress. The change $(\Delta)$ in the DEE of the cervico-thoracic muscles also correlated with the change in whole-body $\mathrm{EE}(r=0.89, p=0.007)$. 

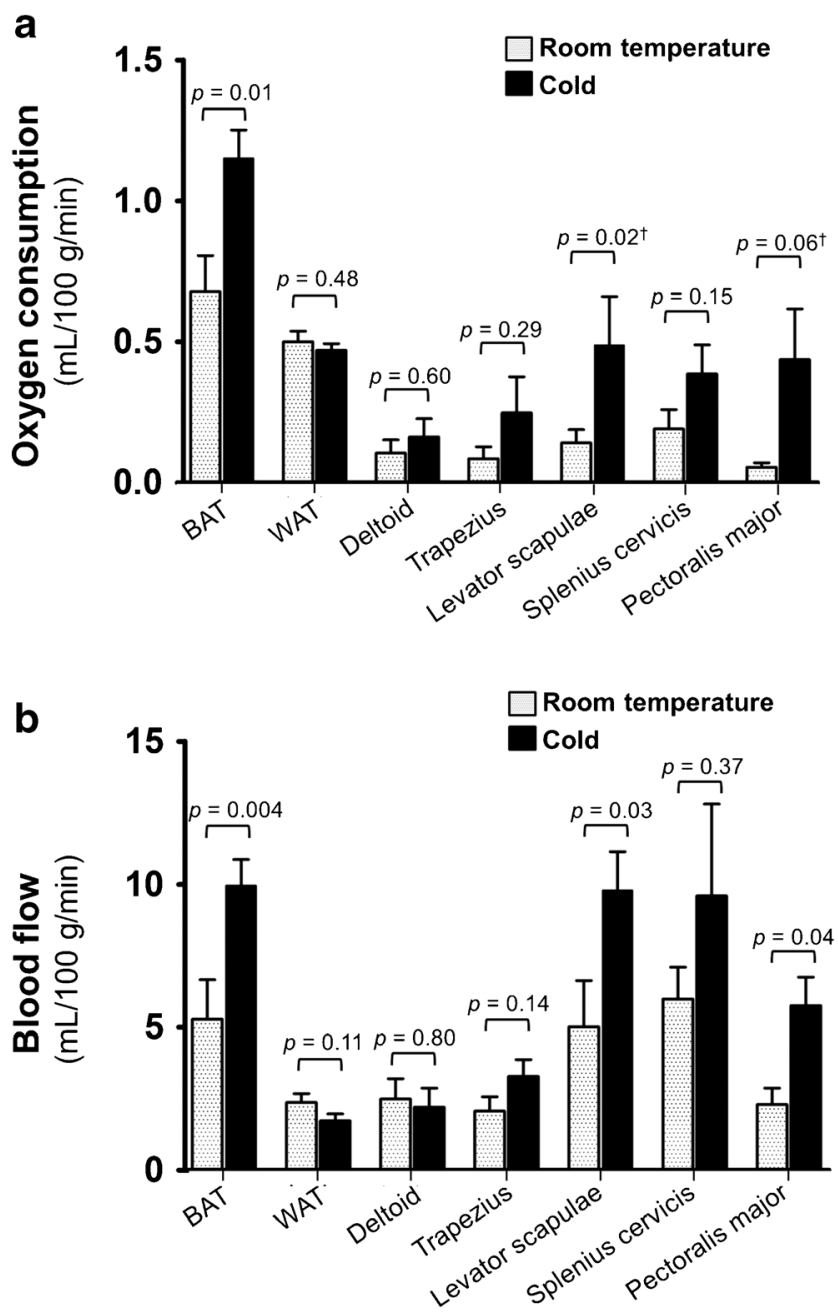

Fig. 4 a: Metabolic rate of oxygen consumption $\left(\mathrm{MRO}_{2}\right)$ of BAT, WAT and different cervico-thoracic muscles during room temperature and cold, calculated from $\left[{ }^{15} \mathrm{O}\right] \mathrm{O}_{2}$ PET scans; results are shown as means $\pm \mathrm{SEM}$. b: Blood flow in BAT, WAT, and additional muscles during room temperature and cold calculated using $\left[{ }^{15} \mathrm{O}^{-} \mathrm{H}_{2} \mathrm{O}\right.$ PET scans; results are shown as means \pm SEM. Wilcoxon rank-sum test
When the change in the BAT DEE was also taken into account along with the change in muscles DEE, the correlation improved $(r=0.91, p=0.005$, Fig. $5 b)$.

Signifying tissue metabolism, BAT-associated DEE was in direct relationship with BAT blood flow both during RT $(r=0.97, p<0.001$, Fig. 6a) and cold $(r=0.79, p=0.04$, Fig. 6b). Moreover, it also had a direct relationship with BAT NEFA per depot uptake both during RT and under cold stress (RT: $r=0.90, p=0.006$; cold: $r h o=0.86, p=0.01$, Fig. 7).

\section{Discussion}

The present study addresses BAT-specific contribution to cold-induced thermogenesis (CIT), previously speculated to be primarily a BAT response in a number of reports $[3,7,9$, 22]. In addition, BAT substrate oxidative metabolism with particular reference to circulatory NEFAs is also addressed. Our study is one of the few attempts to evaluate oxygen consumption of BAT in humans using $\left[{ }^{15} \mathrm{O}\right] \mathrm{O}_{2}$ PET imaging. A previous study by Muzik et al. [11] has shown an association between BAT oxygen consumption and semi-quantitative glucose uptake measure, SUVs. However, it has been suggested that the main substrate of activated BAT is fatty acid [10], and glucose is used as a secondary substrate. Therefore, it was critical to establish how much of the fatty acid uptake is associated with oxidative metabolism of BAT both at RT and during cold stimulus. One of the advantages of measuring oxygen consumption in BAT using $\left[{ }^{15} \mathrm{O}\right] \mathrm{O}_{2}$ PET imaging is that it is a direct and non-invasive technique, which is not influenced by substrate availability and utilisation rate as might be the case with $\left[{ }^{18} \mathrm{~F}\right] \mathrm{FDG}$ and $\left[{ }^{18} \mathrm{~F}\right] \mathrm{FTHA}$ radiotracers [23]. This technique shows the overall oxidative metabolic rate of BAT, which also includes oxidation of all known possible substrates
Fig. 5 The change $(\Delta)$ in whole body energy expenditure (EE) during RT and cold stress, measured with indirect calorimetry, was found to be directly correlating with BAT mass (a) and also with the sum of the change $(\Delta)$ in the cervico-upper thoracic muscle-associated daily energy expenditure (DEE) and $\triangle$ BATassociated DEE, measured with $\left[{ }^{15} \mathrm{O}\right] \mathrm{O}_{2}$ PET imaging (b) a

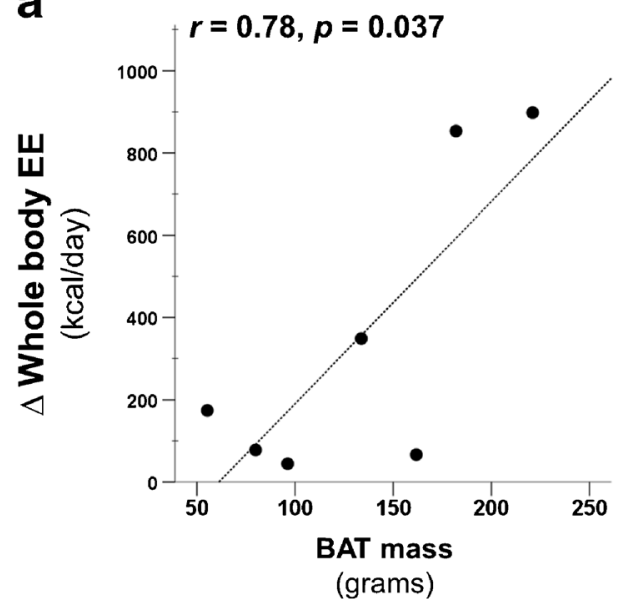

b

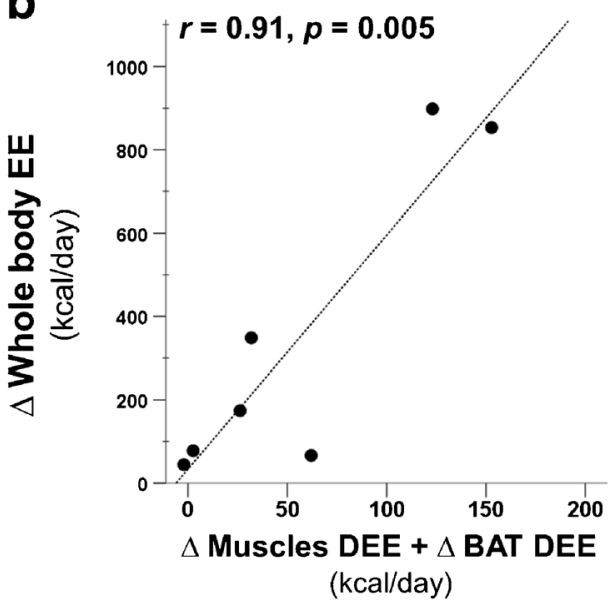


Fig. 6 BAT-associated DEE correlated with BAT blood flow both at room temperature (a) and also during cold stimulus (b)

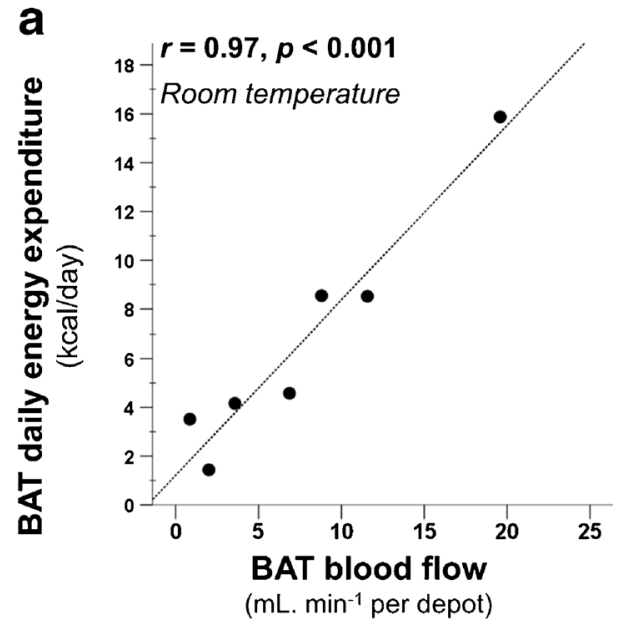

for BAT consumption, e.g. glucose, fatty acid, ketone bodies, or amino acids.

Based on our data, we estimated that under mild cold stimulation the BAT-associated DEE of the cervico-upper thoracic depot is approximately $10 \pm 5 \mathrm{kcal} /$ day which is close to the values reported earlier by Muzik et al. [11]. Whole-body EE increased significantly during cold stress; however, we did not observe any significant linear relationship between BAT DEE and whole-body EE which is indicative that the cervico-upper thoracic BAT does not contribute as a single and linear factor to whole-body EE. Change in BAT-associated DEE (4 $\pm 3 \mathrm{kcal} /$ day) accounted for only $1 \%$ of the total wholebody CIT (351 $\pm 372 \mathrm{kcal} /$ day), while once DEE of cervicothoracic muscles (in our FOV) was also taken into account they contributed $86 \pm 68 \mathrm{kcal} /$ day. However, the rest of the CIT could not be accounted for due to limited FOV of our PET scanner. The study by Blondin et al. [24] supports these findings, where it has been shown that the cold exposed skeletal muscles manifest more than $50 \%$ of the total systemic glucose uptake compared to $1 \%$ in BAT.

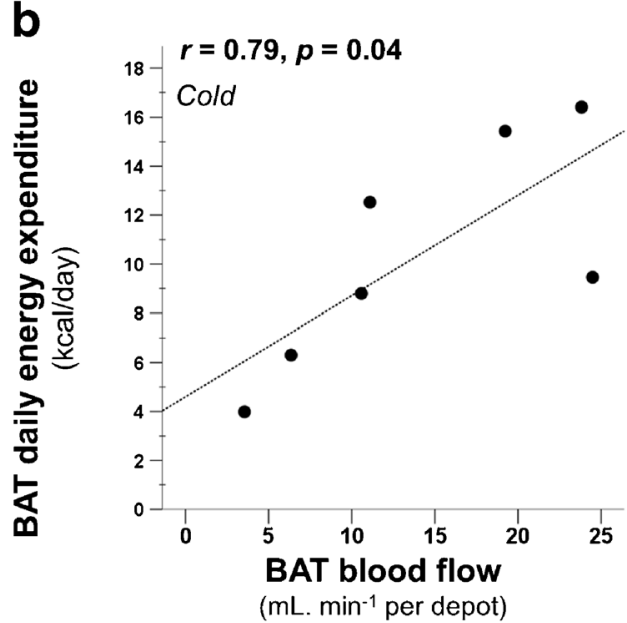

Acute cold stress in humans results in autonomic responses of cutaneous vasoconstriction, in order to limit heat loss, and activation of SNS [25]. Cutaneous vasoconstriction decreases skin temperature (Table 2), and elevation of circulatory catecholamine, as a consequence of SNS activation, triggers lipolysis in adipocytes. Increased lipolysis raises the plasma triglyceride levels (Table 2) likely to fuel NST [26]. Heat loss exceeding NST leads to an increase in shivering thermogenesis [25]. Therefore, in order to keep the subjects in the NSTzone, in our cooling protocol we increased the temperature of the cooling blanket once there were visual signs of shivering or the subject verbally reported shivering; however, based on our data it appears that shivering got activated on a microscale level in certain muscles before being observable or perceived by the individual. $\mathrm{MRO}_{2}$ in the deltoid and trapezius muscle did not increase significantly in our study, which suggests that shivering was not taking place in the appendicular skeletal muscles, and therefore, we deduce that possibly shivering perception in humans is only associated with shivering in the muscles of the appendages. Another explanation, other than
Fig. 7 BAT-associated DEE correlated with BAT NEFA uptake both at room temperature (a) and also after cold stimulus (b). Abbreviation: NEFA, nonesterified fatty acid a

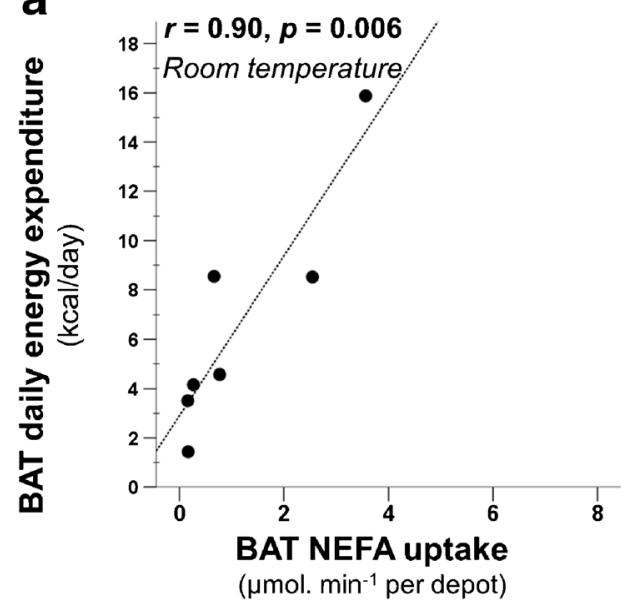

b

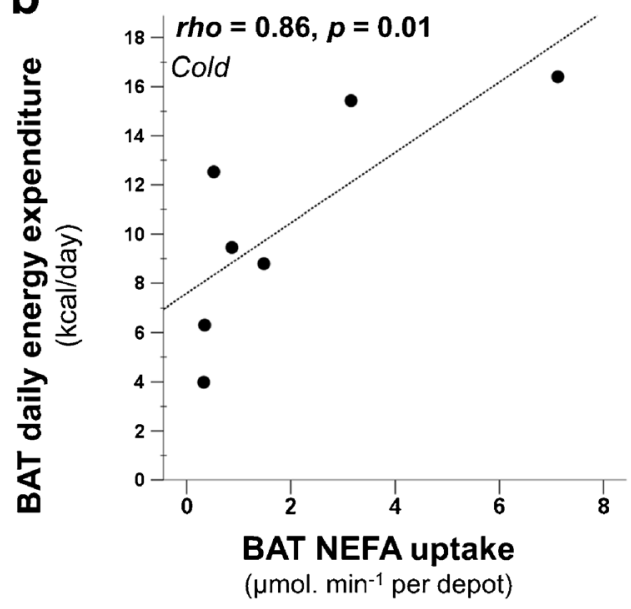


the shivering for the increase in $\mathrm{MRO}_{2}$ in deep muscles, could also be the presence of mitochondrial uncoupling proteins as thermogenic agents in response to cold. These agents have been previously identified in rodent and human skeletal muscles [27-29]. Irrespective of the underlying mechanism of thermogenesis in skeletal muscles, our data suggests that the deep, centrally located cervico-thoracic muscles contribute to cold-induced thermogenesis along with BAT, and that they are a rather major contributor to CIT. Although, interestingly, the BAT mass correlated with CIT (Fig. 5), consistent with earlier findings [22], it appears that BAT possibly has an endocrine role in CIT, while the muscles surrounding BAT are the major contributor. Further studies that unravel secretory factors of BAT during cold stimulus, in conjunction with BAT oxygen consumption, are needed to draw concrete conclusions.

The strong positive correlation between BAT DEE and blood flow signifies the interdependence of both processes (Fig. 6). This may indicate that either UCP-1 mediated heat produced in BAT is distributed via circulation, or that the perfusion increases to provide oxygen and substrates for active BAT (Fig. 6). We further found that BAT-associated DEE is in correlation with its NEFA uptake both during RT and cold stress (Fig. 7). This suggests that BAT is also oxidizing substrates at RT although in a modest quantity compared to cold conditions, which signifies that BAT could already have ongoing thermogenesis at RT; however, it is not established how much of the UCP-1 protein in BAT mitochondria are uncoupled at RT. We also estimated that if the calculated fatty acids taken up via the blood stream in BAT, during cold stimulus, undergo complete oxidation they will amount to an average of $4.4 \mathrm{kcal} / 100 \mathrm{~g} /$ day (range $1.3-13.2 \mathrm{kcal} / 100 \mathrm{~g} /$ day). Comparing the values of both energy consumption following fatty acids complete oxidation and BAT-associated DEE, we observed a highly variable proportional contribution of circulatory NEFA towards the total BAT-associated DEE ( $14 \%$ to $146 \%$, Supplementary Table 1). This variation was marginally linked to the quantity of stored triglycerides within BAT depots (measured as CT radiodensity in Hounsfield units), where less radiodense BAT depots (possessing more intracellular lipids) were found to require less contribution of NEFA from blood circulation ( $r=0.72, p=0.068$, Supplementary Fig. 1). Other factors that may play a role in determining the quality and quantity of oxidised substrates could not be established with the current methods. Although it has been indicated that human BAT relies on the endogenous fatty acids following intracellular triglyceride breakdown [30]; there is currently no available tool that has the ability to measure the quantity, as well as the proportional contribution of these consumed lipids in vivo as a result of cold exposure. In our study we also could not determine whether circulatory NEFA taken up by BAT are directly consumed as a substrate for thermogenic respiratory chain reactions, or whether the NEFA replenish the intracellular triglyceride stores subsequent to endogenous production of fatty acids. Nevertheless, it is worth mentioning that energy content of fully oxidised NEFA taken up by BAT, reported here and previously [30], and glucose uptake $[4,7,31]$ is of the same order of magnitude, although their proportional contribution during cold stimulus is yet to be determined.

The other limitations of our study include small number of study subjects which is due to the complexity of the radioactive oxygen PET scans. The complexity includes the production of the $\left[{ }^{15} \mathrm{O}_{0} \mathrm{O}_{2}\right.$, the inhalation protocol, the PET image acquisition, and the kinetic modelling of this very rapidly defusing and decaying radiotracer. Moreover, relatively shorter half-life of ${ }^{15} \mathrm{O}$ and the limited FOV of our scanner restricted assessment of possible BAT depots in further locations [32]; therefore, the present results may underestimate BAT contribution to whole body EE. Additionally, due to our aforementioned limitations, the relationship of metabolism in other organs to BAT oxidative metabolism could not be established.

\section{Conclusion}

We conclude that cold stimulation in humans increases BATassociated EE and whole-body EE; however, BAT is minor contributor to this whole-body cold-induced thermogenesis, while deeper centrally located neck muscles, along with the pectoral muscles are among the major contributors to thermogenesis. Moreover, in BAT, both during RT and cold stress, oxygen consumption is interlinked with the circulatory uptake of NEFA.

Acknowledgments The authors wish to thank all the study subjects enrolled in this study for their cooperation and also all the technical staff of Turku PET centre for their assistance. The study was financially supported by the Academy of Finland ( 259926 \& 265204 \& 292839 \& 269977), the Paulo Foundation, the Finnish Cultural Foundation Southwest Finland Regional Fund, the Turku University Hospital Research Funds and by the European Union (EU FP7 project 278373; DIABAT). The study was conducted within the Finnish Centre of Excellence in Cardiovascular and Metabolic Diseases supported by the Academy of Finland, University of Turku, Turku University Hospital and Åbo Akademi University.

\section{Compliance with ethical standards}

Conflict of Interest The authors declare that they have no conflict of interest.

Ethical approval All procedures performed in studies involving human participants were in accordance with the ethical standards of the institutional research committee and with the 1964 Helsinki Declaration and its later amendments or comparable ethical standards.

Informed consent Informed consent was obtained from all individual participants included in the study before any clinical assessments in screening. 
Open Access This article is distributed under the terms of the Creative Commons Attribution 4.0 International License (http:// creativecommons.org/licenses/by/4.0/), which permits unrestricted use, distribution, and reproduction in any medium, provided you give appropriate credit to the original author(s) and the source, provide a link to the Creative Commons license, and indicate if changes were made.

\section{References}

1. Nedergaard J, Golozoubova V, Matthias A, Asadi A, Jacobsson A, Cannon B. UCP1: the only protein able to mediate adaptive nonshivering thermogenesis and metabolic inefficiency. Biochim Biophys Acta. 2001;1504:82-106.

2. Cypess AM, Lehman S, Williams G, Tal I, Rodman D, Goldfine $\mathrm{AB}$, et al. Identification and importance of brown adipose tissue in adult humans. N Engl J Med. 2009;360:1509-17.

3. van Marken Lichtenbelt WD, Vanhommerig JW, Smulders NM, Drossaerts JM, Kemerink GJ, Bouvy ND, et al. Cold-activated brown adipose tissue in healthy men. N Engl J Med. 2009;360: $1500-8$.

4. Virtanen KA, Lidell ME, Orava J, Heglind M, Westergren R, Niemi $\mathrm{T}$, et al. Functional brown adipose tissue in healthy adults. $\mathrm{N}$ Engl $\mathrm{J}$ Med. 2009;360:1518-25.

5. Cinti S. The role of brown adipose tissue in human obesity. Nutr Metab Cardiovasc Dis. 2006;16:569-74.

6. Cohade C, Osman M, Pannu HK, Wahl RL. Uptake in supraclavicular area fat ("USA-Fat"): description on 18F-FDG PET/CT. J Nucl Med. 2003;44:170-6.

7. Orava J, Nuutila P, Lidell ME, Oikonen V, Noponen T, Viljanen T, et al. Different metabolic responses of human brown adipose tissue to activation by cold and insulin. Cell Metab. 2011;14:272-9.

8. Saito M, Okamatsu-Ogura Y, Matsushita M, Watanabe K, Yoneshiro T, Nio-Kobayashi J, et al. High incidence of metabolically active brown adipose tissue in healthy adult humans: effects of cold exposure and adiposity. Diabetes. 2009;58:1526-31.

9. Yoneshiro T, Aita S, Matsushita M, Kameya T, Nakada K, Kawai Y, et al. Brown adipose tissue, whole-body energy expenditure, and thermogenesis in healthy adult men. Obesity (Silver Spring). 2011;19:13-6.

10. Ma SW, Foster DO. Uptake of glucose and release of fatty acids and glycerol by rat brown adipose tissue in vivo. Can J Physiol Pharmacol. 1986;64:609-14.

11. Muzik O, Mangner TJ, Leonard WR, Kumar A, Janisse J, Granneman JG. 15O PET measurement of blood flow and oxygen consumption in cold-activated human brown fat. J Nucl Med. 2013;54:523-31.

12. Cypess AM, Haft CR, Laughlin MR, Hu HH. Brown fat in humans: consensus points and experimental guidelines. Cell Metab. 2014;20:408-15.

13. DeFronzo RA, Tobin JD, Andres R. Glucose clamp technique: a method for quantifying insulin secretion and resistance. Am J Physiol. 1979;237:E214-23.

14. Saari T, Raiko J, Niemi T, Taittonen M, Laine J, Savisto N, Haaparanta-Solin M, Nuutila P, Virtanen KT. Impaired brown adipose tissue fatty acid metabolism in obese subjects. Diabetologia. 2014;57[Supp11]:S14-S14.

15. Iida H, Jones T, Miura S. Modeling approach to eliminate the need to separate arterial plasma in oxygen-15 inhalation positron emission tomography. J Nucl Med. 1993;34:1333-40.

16. Kudomi N, Hirano Y, Koshino K, Hayashi T, Watabe H, Fukushima $\mathrm{K}$, et al. Rapid quantitative $\mathrm{CBF}$ and $\mathrm{CMRO}(2)$ measurements from a single PET scan with sequential administration of dual (15)O-labeled tracers. J Cereb Blood Flow Metab. 2013;33: 440-8.

17. Nuutila P, Peltoniemi P, Oikonen V, Larmola K, Kemppainen J, Takala T, et al. Enhanced stimulation of glucose uptake by insulin increases exercise-stimulated glucose uptake in skeletal muscle in humans: studies using [15O]O2, [15O]H2O, [18F]fluoro-deoxyglucose, and positron emission tomography. Diabetes. 2000;49: 1084-91.

18. Oikonen V, Nuutila P, Sipilä H, Tolvanen T, Peltoniemi P, Ruotsalainen U. Quantification of oxygen consumption in skeletal muscle with PET and oxygen-15 bolus. Eur J Nucl Med. 1998;25: 1151.

19. WEIR JB. New methods for calculating metabolic rate with special reference to protein metabolism. J Physiol. 1949;109:1-9.

20. Merilainen PT. Metabolic monitor. Int J Clin Monit Comput. 1987;4:167-77.

21. Leonard WR. Measuring human energy expenditure and metabolic function: basic principles and methods. J Anthropol Sci. 2010;88: 221-30.

22. Chen KY, Brychta RJ, Linderman JD, Smith S, Courville A, Dieckmann W, et al. Brown fat activation mediates coldinduced thermogenesis in adult humans in response to a mild decrease in ambient temperature. J Clin Endocrinol Metab. 2013;98:E1218-23.

23. Klein LJ, Visser FC, Knaapen P, Peters JH, Teule GJ, Visser CA, et al. Carbon-11 acetate as a tracer of myocardial oxygen consumption. Eur J Nucl Med. 2001;28:651-68.

24. Blondin DP, Labbe SM, Phoenix S, Guerin B, Turcotte EE, Richard $\mathrm{D}$, et al. Contributions of white and brown adipose tissues and skeletal muscles to acute cold-induced metabolic responses in healthy men. J Physiol. 2015;593:701-14.

25. Stocks JM, Taylor NA, Tipton MJ, Greenleaf JE. Human physiological responses to cold exposure. Aviat Space Environ Med. 2004; 75:444-57.

26. Geerling JJ, Boon MR, Kooijman S, Parlevliet ET, Havekes LM, Romijn JA, et al. Sympathetic nervous system control of triglyceride metabolism: novel concepts derived from recent studies. J Lipid Res. 2014;55:180-9.

27. Simonyan RA, Jimenez M, Ceddia RB, Giacobino JP, Muzzin P, Skulachev VP. Cold-induced changes in the energy coupling and the UCP3 level in rodent skeletal muscles. Biochim Biophys Acta. 2001;1505:271-9.

28. Mollica MP, Lionetti L, Crescenzo R, Tasso R, Barletta A, Liverini $\mathrm{G}$, et al. Cold exposure differently influences mitochondrial energy efficiency in rat liver and skeletal muscle. FEBS Lett. 2005;579: 1978-82.

29. Wijers SL, Schrauwen P, Saris WH, van Marken Lichtenbelt WD. Human skeletal muscle mitochondrial uncoupling is associated with cold induced adaptive thermogenesis. PLoS ONE. 2008;3, e1777.

30. Ouellet V, Labbe SM, Blondin DP, Phoenix S, Guerin B, Haman F, et al. Brown adipose tissue oxidative metabolism contributes to energy expenditure during acute cold exposure in humans. J Clin Invest. 2012;122:545-52.

31. Orava J, Nuutila P, Noponen T, Parkkola R, Viljanen T, Enerback S, et al. Blunted metabolic responses to cold and insulin stimulation in brown adipose tissue of obese humans. Obesity (Silver Spring). 2013;21:2279-87.

32. Heaton JM. The distribution of brown adipose tissue in the human. J Anat. 1972;112:35-9. 